\title{
WALTER BENJAMIN E A INFÂNCIA COMO REMEMORAÇÃO
}

Idenilza Barbosa Lima de Lima

Para Artemis Veiga, in memoriam.

\begin{abstract}
RESUMO
Este texto objetiva analisar o papel reservado à infância em alguns escritos da obra de Walter Benjamin, principalmente, algumas questões pertinentes ao conceito de rememoração. O filósofo apresenta a criança como observador das ruas da metrópole em um percurso de aventuras e descobertas até à proteção que recebe dos adultos em casa. A hipótese é de que a criança encontra-se na cidade, mas à margem desta, porque suas observações quase todas são silenciadas pelo modo de vida dos adultos. Concluímos que Walter Benjamin resgata a infância como modo de rememoração, potencializada por levar à reflexão razões de existência no presente.
\end{abstract}

Palavras-chave: Infância. Cidade. Rememoração. Walter Benjamin.

\section{WALTER BENJAMIN AND THE CHILDHOOD AS A RECOLLECTION}

ABSTRACT

This text aims to analyze the role reserved for childhood in some writings of Walter Benjamin, especially some issues relevant to the concept of recollection. The philosopher presents the child as an observer of the streets of the metropolis in a journey of adventures and discoveries to the protection it receives from adults at home. The hypothesis is that the child is in the town, but on the fringes of this, because their comments almost all are silenced by the way of life of adults. We conclude that Walter Benjamin rescues the childhood for recollection, potentized by lead to reflection of existence in the present reasons.

Key-words: Chidhood. Metropolis. Recollection. Walter Benjamin.

\section{A infância nos escritos de Walter Benjamin}

Nos escritos de Walter Benjamin qualquer que seja o tema, o elemento principal é a modernidade, tendo-a como referência e a partir da qual põe em relevo a discussão em torno do drama humano presente ora na literatura, ora no palco, na escola, no trabalho e nas ruas da metrópole, desde a infância à juventude. Em relação à infância, seus escritos nas publicações brasileiras encontram-se nos livros Magia e Técnica, Arte e Política - Obras Escolhidas (1994), Infância em Berlim, por volta de 1900 - Obras Escolhidas II (1987) e, Reflexões: a criança, o brinquedo, a 
educação (1984). Tais escritos contemplam narrativas sobre a criança em situação de observador do mundo capaz de nomear e clarificar o ambiente no qual convive com 0 adulto.

Neste estudo, analisamos alguns textos significativos para a compreensão da concepção de infância em Walter Benjamin, textos os quais se encontram no livro Infância em Berlim, por volta de 1900. Este livro, dedicado ao filho Stefan, segundo o próprio Benjamin, "não se trata, de forma alguma, de relatos ao modo de crônicas e sim de uma ou outra expedição às profundezas da memória (...)". ${ }^{1}$ Marques (2009) corrobora esse pensamento, pois assinala que tais escritos ao ressaltarem a infância problematizam a questão da individualidade, o que só seria possível na modernidade em um modelo de vida burguês,

\begin{abstract}
mas sobretudo porque sua preocupação parece não ser simplesmente narrar as memórias de uma infância pessoal, mas, ao fazê-lo, resgatar também imagens nas quais se deposita uma memória mais ampla, que ultrapassa a experiência individual para alcançar as marcas da experiência histórica. ${ }^{2}$
\end{abstract}

Consideramos, nesse aspecto, o sentido de infância aplicado a um significante, a saber, a rememoração. Konder (1999) cogita que a rememoração estaria a serviço da reflexão não só sobre o fenômeno que passou, mas também sobre o que teria acontecido. Logo, percebe-se que a temporalidade verbal -o pretérito- se dá como existência também na atualidade -futuro do pretérito- e, desse modo, encontra-se amalgamada ao contexto da historicidade do sujeito, sujeito ator de sua história.

Em "Um anjo de Natal", escrito que faz parte do livro "Infância em Berlim, por volta de 1900" (1932-38/1992), o primeiro cenário descrito é o das ruas da metrópole. No percurso de casa à escola a criança se mantém atenta ao que se passa na cidade e, a narrativa sobre o cotidiano, envolve-o com a poesia e parceira de seus escritos (1932-38/1992).

Tudo começava com as árvores de Natal. Certa manhã, quando íamos à escola, víamos presas às esquinas das ruas as marcas verdes que

1 SCHOLEM. Correspondência, 1933-1940. São Paulo: Editora Perspectiva, 1993, p. .

2 MARQUES. Berlim revisitada ou a cidade da memória: "Infância em Berlim por volta de 1900". In: Artefilosofia, Ouro Preto, n. 6, 2009, p.35. 
pareciam segurar a cidade nas suas centenas de esquinas e ângulos, como se ela fosse um enorme presente de Natal. ${ }^{3}$

Neste sentido, consideramos que Walter Benjamin apresenta alguns elementos que fazem com que a infância surja como mote na equação contemporânea, qual seja, alegoria =criança $=$ modernidade. De tal modo essa equação se mantém presente na obra benjaminiana que é possível observar como a infância revigora o conceito de alegoria usado por Benjamin em consonância aos apelos do campo social que determinam sua narrativa sobre a vida do homem nos labirintos da metrópole.

Nesta linha de raciocínio, vemos os elementos que fazem parte da trajetória da criança: o parque, os animais, o quarto de dormir, a escola, objetos pessoais, monumentos, personagens históricos etc. Todos estes elementos compõem tanto a experiência (erfahung) quanto a vivência (erlebnis) ${ }^{4}$. No sentido da experiência, que corresponde ao choque em Benjamin e ao trauma em Freud (SANTIAGO, 2012), tais elementos configuram o cotidiano da cidade e têm como função viabilizar a socialização. A experiência seria, neste aspecto, a verdadeira catapulta para o humano, passagem para à vida na metrópole, uma vez que somente através desses elementos a criança se submete e se torna membro do corpo social. No âmbito da experiência, portanto, o que encontramos nos escritos é a possibilidade, o potencial para a humanização da criança.

Assim pensando, vemos, por exemplo, a figura de Baudelaire não só como o poeta-flauner, cosmopolita, observador das avenidas nas quais se deixa iluminar com as histórias dos "passantes", mas que também ilumina com o reflexo de sua poesia as vitrines de Paris. Paris, cidade modelo da modernidade, tanto pelo que destrói quanto pelo que constrói. Também, Baudelaire é figura emblemática de um modelo do trabalhador do capitalismo que tem a produção diretamente ligada à necessidade de sobrevivência. Paralelo ao caminhar do poeta-flauner, encontramos a criança benjaminiana que no seu caminhar pela rua é obviamente alegórica, pois como nos ensina Matos (1999), em Benjamin,

3 p. 171.

1 Desenvolvemos uma reflexão sobre o tema da experiência/vivência em nossa dissertação de mestrado "Cantiga do despertar: uma leitura benjaminiana da criança na clínica psicanalítica" (UNIFOR/2007). 
Toda a infância é quebra da continuidade temporal, pois coloca entre as épocas da vida uma camada de experiências que esquecemos, mas cuja intensidade foi tal que a fulgurância de uma recordação fragmentária é suficiente para reabrir nosso acesso à história. ${ }^{5}$

Trata-se da intensidade do momento, segundo os escritos de Benjamin, e que mostra uma criança voltada para o ambiente do qual participa ativamente. Com suas ações a criança benjaminiana nos mostra o que corresponderia a uma dependência relativa, pois sai de casa tanto para revisitar os locais conhecidos e apreciados como para brincar e aventurar-se nos caminhos desconhecidos.

Neste aspecto, o texto "Panorama Imperial"6 aproxima o leitor desse momento de liberdade em que a criança aprecia um produto da modernidade com imagens "fabricadas". E, como na modernidade a vida é uma "fábrica de ilusões" - o diferencial da criança é reconhecer-se como parte dessa a ilusão, pois ao armar a cena lúdica, todo objeto, qualquer resto, se torna um brinquedo.

Observamos que a esse tipo de ilustração Benjamin recorre em "Á caça de borboletas". Neste relato, nas férias de verão a criança se hospedava na casa de campo com a família, desvelando o adulto não somente saudosista, mas também ignorante da descontinuidade do Tempo. Por não compreender que apenas as lembranças não são suficientes para trazer de volta o ânimo, a alma do momento, o adulto-narrador desvia seu olhar para o bosque em busca do imprevisível, do inesperado, que possa surpreendê-lo. Eis porque a criança recordada também é a aquela que como as borboletas "desviaram dos caminhos de jardim bem tratados, atraindo-me para bosques" 7 .

Assim como Baudelaire, o poeta-flauner, em suas aventuras pelas ruas de Paris, torna-se seletivo, em uma verdadeira "construção de memória"

Não conhecer bem os percursos de uma cidade não tem muito que se the diga. Perder-se, no entanto, numa cidade, tal como é possível acontecer num bosque, requer instrução. ${ }^{9}$

${ }^{5}$ MATOS. O iluminismo visionário: Benjamin, leitor de Descartes e Kant. São Paulo: Brasiliense, 1999, p. 62-63.

6 BENJAMIN. Rua de sentido único, 1992, p. 118.

7 BENJAMIN. Opus cit, 1992, p. 124.

8 RIBEIRO. 2011.

9 BENJAMIN. Opus cit, 1992, p. 115.

Idenilza Barbosa Lima de Lima - Doutoranda em Psicologia Social pela Universidade J. Kennedy - UK - AR, psicanalista do Serviço de Reabilitação do Núcleo de Atenção Médica Integrada da UNIFOR-CE. Brasileira, residente em Fortaleza - CE, E-mail: limadelima@gmail.com 
O narrador compõe um quadro de polarização: rua/lar, rua/escola, pobre/rico, festas/dramas, sexo/morte. Ao fazer parte do cotidiano dos adultos, é natural que em suas reminiscências a criança se apresente no espaço/tempo de transição entre o acontecido e as lembranças. É neste caminho de reminiscência que acontece o "perder-se na cidade".

Nesses escritos, temos então dois polos identificados. O primeiro diz respeito ao narrador que se anima a penetrar no desejo infantil, sonhos e acontecimentos recordados; no segundo, temos a criança que participa dos acontecimentos voltando-se para o novo, aventurando-se, cosmopolita, observando as contínuas transformações/destruições na metrópole.

\section{A criança benjaminiana como observadora da metrópole}

No texto "A coluna da vitória", a criança se vê diante do monumento ao dia de Sedan, data em que o povo celebra a vitória sobre as tropas de Napoleão III e posterior capitulação na cidade francesa de Sedan. Neste encontro o narrador recupera o antigo desejo infantil de unidade narcísica, que sendo mítico comparece em vários momentos da vida, nomeadamente, nos momentos de conflitos e de sofrimento, oscilando entre fantasias de onipotência e de ameaça de aniquilamento. São sentimentos gerados por fantasias, mas que a guerra potencializa, pois o sujeito vê o próprio aniquilamento não mais como possibilidade, mas como fato inteiramente viável.

A guerra evoca também o mito da unificação dos povos, estes que se encontram constantemente ameaçados por guerras pela ocupação de territórios. Embora Benjamin não se sinta capaz de abdicar de suas convicções a respeito da guerra, esta se tornaria o pilar sobre o qual sustentará suas interrogações; visitará antigos argumentos sobre o fato de que o povo nada sabe dos motivos que o levam à guerra. Assim, o narrador adverte:

Com a derrota dos franceses em Sedan, a história universal parecia ter-se afundado na sua gloriosa sepultura, sobre a qual esta coluna se erguia como pedra tumular e na qual desembocava a Alameda da Vitória. ${ }^{10}$

\footnotetext{
${ }^{10}$ BENJAMIN, Opus cit, p. 120.

Idenilza Barbosa Lima de Lima - Doutoranda em Psicologia Social pela Universidade J. Kennedy - UK - AR, psicanalista do Serviço de Reabilitação do Núcleo de Atenção Médica Integrada da UNIFOR-CE. Brasileira, residente em Fortaleza - CE, E-mail: limadelima@gmail.com
} 
Ao pôr em cena o mito da unificação, o narrador problematiza a questão da identidade de cada povo. Tal identidade vinha sofrendo mudanças ao longo da história europeia, às vezes mais ou menos radicais. O nome Alemanha, por exemplo, se constitui a partir do substantivo deutsch, cuja origem evoca infindáveis guerras territoriais. Mas quer se encontre no império dos francos sob o comando de Carlos Magno, quer estejam os teutões subjugados por Caio Mario, o nome Alemanha - Germania em latim- desvela em si o homem de guerra, o homem da lança. Tal fato não é ignorado pelo narrador. O ceticismo da criança ao longo do texto orienta o leitor:

Todavia, não compreendera bem o que significavam os canos de canhão que o formavam: se os franceses teriam ido para a guerra com canhões de ouro ou se o ouro que lhes havíamos extorquido tivesse servido para fundir esses canhões. ${ }^{11}$

Tratada por Benjamin como mais uma motivação para revelar suas ideias, a guerra de Sedan unifica o adulto que narra os acontecimentos à criança que participa deles de modo esperançoso, distraída com as explicações de origem oficial ou mesmo familiar. Afinal, o que o dia de Sedan traz para a criança além de ser mais um feriado para ficar ao lado da família, divertindo-se, passeando? Seria esse o pensamento do leitor, não fosse o narrador capaz de argumentar:

Os heróis cujos feitos ardiam ali na galeria de colunas pareciam-me secretamente tão duvidosos quanto as multidões que, fustigadas por tornados, enxertadas em troncos de árvores sangrentas, congeladas em bloco de glaciar, definhavam na cratera escura. Assim, esta galeria era o inferno, o verdadeiro contraste com o círculo de graça que lá no alto girava em torno da resplandecente Vitória. ${ }^{12}$

"A Mummerehlen" é um texto no qual Benjamin recorre ao tema do folclore para nos comunicar algumas de suas ideais sobre as tradições que se mantêm vivas através da oralidade do povo. A essas incorpora o medo infantil composto por fantasias e que geralmente decorrem de mal entendido - interpretações nas quais predominam os equívocos. Assim acontece conforme o enunciado

\footnotetext{
${ }^{11}$ BENJAMIN, Opus cit, p. 121.

${ }^{12}$ BENJAMIN. Opus cit, 1992, p. 122.
}

Idenilza Barbosa Lima de Lima - Doutoranda em Psicologia Social pela Universidade J. Kennedy - UK - AR, psicanalista do Serviço de Reabilitação do Núcleo de Atenção Médica Integrada da UNIFOR-CE. Brasileira, residente em Fortaleza - CE, E-mail: limadelima@gmail.com 
Numa velha rima para crianças aparece a Muhme Rehlen. Ora, como a palavra "Muhme" nada me dizia, essa criatura transformou-se para mim num espírito: a Mummerehlen. ${ }^{13}$

Benjamin recorre aos elementos que participam do cotidiano da criança, mas que na verdade apenas incorporam a fantasia tornando-a real. Desse modo, vemos a cena no estúdio do fotógrafo ao qual compara a uma "câmara de tortura". A criança vê sua imagem tomar formas distintas, inusitadas, a partir do figurino igualmente inusitado em um ambiente fortemente marcado pela tradição: a fotografia em família, a fotografia dos herdeiros tendo como fundo a paisagem a ser conquistada, mas da qual Benjamin nada quer saber.

As palavras são usadas para encantar, seduzir, mascarar. Benjamin descobre muito cedo que talvez desvendar o mistério das palavras venha a ser sua tarefa por toda a vida, por isso, a criança tenta desvelar o mistério que há por traz das palavras enquanto o narrador se abstém na vã tentativa de coordenar lembranças e significados como que atraído por mais esse mistério da rememoração.

\section{Da infância como rememoração}

O inverno em Berlin é outro motivo para que a criança participe ativamente da vida do adulto. Ao sair para fazer compras, a mãe solicita a presença da criança que ao longo do passeio se distrai com o par de opostos claro/escuro. Na obra de Benjamin, encontramos uma combinação de fragmentos os quais iluminam de forma gradual nosso pensamento, nossa reflexão a respeito de suas ideias sobre a modernidade. Tal combinação ora nos leva a caminhos às vezes já visitados em algum outro momento, outras vezes nos leva ao inesperado e temos a sensação de que caímos em queda livre do alto de suas ideias.

Benjamin, em "Fim de tarde de inverno" espelha no leitor a criança que caminha sem dar-se conta do itinerário: "Era uma Berlim escura e desconhecida que se estendia à minha frente à luz dos candeeiros"14. Assim, a criança se distrai com as sombras projetadas nas fachadas das casas, porém, à luz dos candeeiros, seu olhar não alcança o interior que permanece velado por cortinas, persianas referências da projeção da individualidade burguesa.

\footnotetext{
${ }^{13}$ BENJAMIN, Opus cit, p. 145.

${ }^{14}$ BENJAMIN, p. 178.
}

Idenilza Barbosa Lima de Lima - Doutoranda em Psicologia Social pela Universidade J. Kennedy - UK - AR, psicanalista do Serviço de Reabilitação do Núcleo de Atenção Médica Integrada da UNIFOR-CE. Brasileira, residente em Fortaleza - CE, E-mail: limadelima@gmail.com 
Ao refazer esse itinerário, em uma Berlim às escuras, o adulto segue as pegadas deixadas por uma infância que é significativa pelo que introduz de surpreendente. Conforme Freitas (2014) ensina sobre a experiência na concepção de Benjamin, para o leitor/narrador

A experiência só é possível numa comunidade onde os indivíduos esqueçam de si mesmos e, distendidos, atentos à história, moldem a imagem de quem a conta. ${ }^{15}$

Nesse sentido, Benjamin relata que a cena de casas iluminadas como cavernas traz à lembrança o postal de uma Praça em Berlim cujas janelas das casas eram transparentes e portas e átrios se misturavam pondo-se à mostra. De igual modo, a infância em Benjamin se entrega às reminiscências. $O$ adulto que narra a história já não é o mesmo de quando na infância passava pela experiência. A experiência em si não existe o que existe é o narrar do acontecimento e este acontecimento se refaz a cada narrativa.

Benjamin se recusa a dar o nome de autobiografia aos seus escritos. Não por capricho, mas por compreender o quanto de reinvenção do presente se faz necessário para se escrever sobre o passado. Um passado que se escreve de modo não linear, forjado pelas reminiscências que se atualizam a cada leitura dessas narrativas, pois o leitor participa com sua livre interpretação. Já não estamos na Idade Média, na qual somente a interpretação vinda dos mosteiros era tida como possibilidade aceita. Benjamin compreende que a modernidade traz para o leitor 0 risco da autoria. Sim, o risco porque o leitor se aventura na organização dos fatos que o narrador, com sua experiência, faz surgir diante do presente.

A temporalidade se perde e resta ao leitor organizar o desejo dessa passagem que não podendo ser cronológica, faz-se espacialmente, daí os lugares e não os sentimentos se tornarem a linha que conduz a narrativa. $O$ fio de Ariadne, por certo, encontra-se com o leitor para que seja trazido de volta das reminiscências benjaminianas.

Gagnebin (2005) acolhe a perspectiva de experiência em Benjamin e assinala:

\footnotetext{
${ }^{15}$ FREITAS, p. 85.

Idenilza Barbosa Lima de Lima - Doutoranda em Psicologia Social pela Universidade J. Kennedy - UK - AR, psicanalista do Serviço de Reabilitação do Núcleo de Atenção Médica Integrada da UNIFOR-CE. Brasileira, residente em Fortaleza - CE, E-mail: $\underline{\text { limadelima@gmail.com }}$
} 
Essa experiência é dupla: primeiro, ela remete sempre à reflexão no adulto que, ao lembrar o passado, não o lembra tal como realmente foi, mas, sim, somente através do prisma do presente projetado sobre ele. ${ }^{16}$

A reflexão acima descreve a necessidade de refazer o percurso da crítica benjaminiana sobre o sentido da experiência na modernidade. Diante do choque do efêmero, signo da modernidade, ao narrador nada é possível, daí a negação da temporalidade, pois é do instante - o choque, que congela a experiência, não sendo mais possível a narrativa. Benjamin encontra na reminiscência o fluxo, a passagem, para a narrativa, que segundo Susan Sontag (1992), deverá primar pela espacialização.

Os temas recorrentes em Benjamin são, caracteristicamente, processos de especializar o mundo: por exemplo, a sua noção das ideias e das experiências como ruínas. Compreender qualquer coisa é compreender a sua topografia, saber como traçar o seu mapa. E saber como se perder nela.

"O Corcundinha" evoca a fantasia de onipotência nas palavras maternas "O Desajeitado manda cumprimentos". A experiência da tradição e a vivência estão presentes neste escrito em que o adulto tenta reatualizar a vivência de choque (Chockerlebnis) em cada momento de sua vida, mas sem (re)significá-lo, por estar preso aos signos da modernidade. Leitor de Freud, Benjamin não poderia deixar de polemizar a vivência de choque em referência ao mundo da modernidade em que o público, a multidão com a mercadoria-fetiche invade o privado, lugar no qual o sujeito resiste através de suas coleções, seus delicados bibelôs, na vã tentativa de "deixar pegadas".

Segundo Benjamin (1994), os homens "aspiram a um mundo em que possam ostentar tão pura e tão claramente sua pobreza externa e interna, que algo descente possa resultar disso."(p.118). Neste sentido, o corcundinha comparece para lembrar da experiência singular que se dá na infância, a experiência que não se pode reproduzir, mas apenas rememorar. Porém, o ato de rememorar cobra seu penhor, sua hipoteca e, desse modo, há uma nova supraexcitação dos sentidos que faz com que as lembranças sejam topograficamente reconstruídas. Em uma cascata de sinônimos, Benjamin transforma a topografia de Berlim em um ato de sedimentação

\footnotetext{
${ }^{16}$ GAGNEBIN, p. 179

${ }^{17}$ SONNTAG, p. 14.
}

Idenilza Barbosa Lima de Lima - Doutoranda em Psicologia Social pela Universidade J. Kennedy - UK - AR, psicanalista do Serviço de Reabilitação do Núcleo de Atenção Médica Integrada da UNIFOR-CE. Brasileira, residente em Fortaleza - CE, E-mail: limadelima@gmail.com 
cujas partículas contidas são os nomes, as casas, os parentescos - línguas e afinidades- a escola, os livros.

As travessuras - brincadeiras infantis, pequenos contratempos, que o saber popular atribui ao corcundinha, logo são transformados em fatalidade. Os sentidos, que se encontram fragmentados pelo choque diário a que são submetidos na metrópole, encontram nas reminiscências um modo de expressão, as lembranças do trauma que só estão acessíveis na consciência. Desse modo, resta ao narrador atribuir os percalços que a vida trouxe a ele, ao corcundinha. Não se trata de uma atribuição aleatória, nem inconsciente. Benjamin encarna na figura do narrador de "Infância em Berlim, por volta de 1900" o homem moderno- também ele amalgamado ao ferro e ao vidro exposto a um só tempo à degradação de ser superado por alguma novidade que possa ser reproduzida.

Construção moderna de um tempo de pobreza e vilania, o sentimento de que a criança herdará os objetos produzidos e reproduzidos pelos homens encontra-se presente também no texto de Benjamin. É neste sentido que "O corcundinha" de Benjamin (1994) vem ao socorro da criança:

\footnotetext{
Não havia para mim uma separação clara entre o mundo que de dia povoava as janelas e aquele que, de noite, esperava o momento certo para me assaltar nos meus sonhos (p. 195).

(...) Só ele me via. E, tanto mais nitidamente, quanto menos eu me via a mim mesmo. ${ }^{18}$
}

O sonho, como manifestação do inconsciente e um dos constructos freudiano, encontra-se presente nas fantasmagorias da metrópole: é o flâneur-poeta em Baudelaire; é a infância como alegoria da modernidade; são os objetos do colecionador; as cortinas nas janelas que não permitem ver o interior das casas, mas, principalmente, é a cidade. A cidade invade o sonho do narrador, como fora um quadro de Dalí, no qual os objetos da realidade se transmutam nas imagens oníricas. A cidade é o corcundinha de Benjamin. Nada assegura ao narrador que a infância deixe de cobrar seu penhor, seus juros. É por isso que a criança benjaminiana, singular, jaz na modernidade, e elevada à categoria de alegoria, dela resta apenas a infância em forma de fragmentos.

\footnotetext{
${ }^{18}$ BENJAMIN. Opus cit, p. 196.

Idenilza Barbosa Lima de Lima - Doutoranda em Psicologia Social pela Universidade J. Kennedy - UK - AR, psicanalista do Serviço de Reabilitação do Núcleo de Atenção Médica Integrada da UNIFOR-CE. Brasileira, residente em Fortaleza - CE, E-mail: limadelima@gmail.com
} 


\section{Conclusão}

A presente leitura da obra de Benjamin (1994) "Infância em Berlin, por volta de 1900" não tem a pretensão de resgatar na literatura o sentido do presente ou a dialética da história tão cara ao filósofo.

Em outras palavras, como observadora, a criança se distrai na topografia da cidade, nos labirintos que os homens constroem - ilhas de trabalhadores distantes das galerias nas quais as mercadorias estão expostas. Neste aspecto, não há o que resgatar porque nada se perde em Benjamin. "E uma tempestade o impele ao futuro" como acontece ao anjo da história.

A rememoração, traço benjaminiano na produção do que se convencionou chamar de fragmentos, é uma aposta na criança que muito sabe a ponto de poder perder-se na cidade. Assim, nos ensina Benjamin (1989), sobre o flâneur. "A cidade é o antigo sonho humano de labirinto. O flâneur, sem o saber, persegue essa realidade" 19 .

Amalgamado ao ferro e ao vidro, o fantasma do homem moderno percorre as galerias de Paris - cidade modelo da modernidade, com suas mercadorias-fetiches que perdem valor a cada nova temporada da moda. A criança, entretanto, protegida pelo corcundinha, quebra objetos; destrói coleções - convertidas em verdadeiros amuletos contra a fantasmagoria da cidade; derrama sobre si as tintas que colorem as mercadorias, impedindo desse modo sua comercialização; diz palavras que destroem possibilidades de futuro, como no caso do ensaio das famosas "Afinidades eletivas de Goethe"; e, finalmente, impede que o narrador seja apenas mais um intelectual em uma enfadonha academia. Não é atoa que o corcundinha irá acompanhar Walter Benjamin até o fatídico dia de sua passagem em Portbou.

\footnotetext{
${ }^{19}$ BENJAMIN, Opus cit, p. 203.

Idenilza Barbosa Lima de Lima - Doutoranda em Psicologia Social pela Universidade J. Kennedy - UK - AR, psicanalista do Serviço de Reabilitação do Núcleo de Atenção Médica Integrada da UNIFOR-CE. Brasileira, residente em Fortaleza - CE, E-mail: limadelima@gmail.com
} 


\section{REFERÊNCIAS}

BENJAMIN, Walter. Rua de sentido único e infância em Berlim, por volta de 1900. Lisboa, Portugal, Relógio D’Água, 1992.

BENJAMIN, Walter. Experiência e pobreza. In: BENJAMIN, W. Obras Escolhidas. Magia e Técnica. Arte e Política. 7ª ed. São Paulo: Brasiliense, 1994.

BENJAMIN, Walter. O flâneur. In: BENJAMIN, W. Obras Escolhidas III. Charles Baudelaire um lírico no auge do capitalismo. São Paulo: Brasiliense, 1989.

FREITAS, Tatiana M.G. Erfarhung e Erlebnis em Walter Benjamin. In: Revista Garrafa, Rio de Janeiro, n. 33, jan.-jun., p. 72-87, 2014.

GAGNEBIN, Jeanne M. Sete aulas sobre linguagem, memória e história. $2^{\underline{a}}$ ed., rio de Janeiro: Imago, 2005.

MARQUES, Ana M. Berlim revisitada ou a cidade da memória: "Infância em Berlim por volta de 1900". In: Artefilosofia, Ouro Preto, n. 6, p.34-43, 2009.

MATOS, Olgária. O iluminismo visionário: Benjamin, leitor de Descartes e Kant. São Paulo: Brasiliense, 1999.

MURICY, Katia. A alegoria e o inexpressável. In: SOUZA, S. J. ; KRAMER, S. Política, cidade, educação: itinerários de Walter Benjamin. Rio de Janeiro: Contraponto: Ed. PUC-RJ, 2009.

RIBEIRO, Claudia. G. A cidade pelos olhos de Charles Baudelaire e Mário de Andrade. Anais do XV Congresso Nacional de Linguística e Filologia. Disponível em: Cadernos do CNFL, vol. XV, n. 5, t.2 Rio de Janeiro: CiFEFil, 2011.

SANTIAGO, Emanuel. A ambivalência do efeito de choque em Walter Benjamin. 2012. Disponível em: www.http//antenasdemarfim.blogspot.com Acesso em 10 jun. 2015.

SCHOLEM, Gershom. Correspondência, 1933-1940. São Paulo: Editora Perspectiva, 1993.

SONTAG, Susan. Sob o signo de Saturno. In: BENJAMIN, W. Rua de sentido único e infância em Berlim, por volta de 1900. Lisboa, Portugal, Relógio D’Água, 1992. 